\title{
Increased conditioning in rats to a blocked CS after the first compound trial
}

\author{
JULIAN L. AZORLOSA and GEORGE A. CICALA \\ University of Delaware, Newark, Delaware
}

\begin{abstract}
Two experiments examined the effects of increased conditioning to a blocked conditioned stimulus (CS) with increased compound training, using the conditioned suppression procedure. Experiment 1 demonstrated that conditioning to the blocked element increased after the first compound trial but that there was no additional conditioning after 10 compound trials. Conditioning to the blocking CS was also tested and showed no reliable differences among groups given different amounts of compound training. A small increase in conditioning to the pretrained element after the first compound trial suggested that asympotote might not have been reached during pretraining. In Experiment 2 the level of conditioning to the blocking CS was tested extensively. Conditioning to the blocking element did not increase after pretraining when it was conditioned either in a compound or by itself. This provides strong evidence that the pretraining procedures of Experiment 1 did result in asymptotic learning. The results were interpreted as showing that even a completely redundant CS can acquire excitatory strength when it is paired with a significant event such as footshock.
\end{abstract}

Kamin (1969) reported that one element, $X$, of a compound conditioned stimulus (CS) failed to acquire significant conditioning because the other element, A, had been previously paired with the unconditioned stimulus (US). Specifically, Kamin found that noise-shock training blocked subsequent conditioning to the light CS when the light and noise compound was paired with shock. The blocking phenomenon has generated an enormous amount of research and has been one of the most important conditioning paradigms. It has also greatly influenced several recent theories of classical conditioning that were devised partly to account for the phenomenon.

These theories fall into two categories. Theories in the first category (e.g., Rescorla \& Wagner, 1972) emphasize change in the effectiveness of the US. According to the Rescorla-Wagner model, the associative strength gained by a CS on a particular trial is a function of the total conditioning or associative strength available, that is, the asymptote of conditioning (determined by the US) minus the current associative strength of the CS gained from previous trials. A fundamental notion of this model is that there is a limited amount of conditioning to be shared among the extant CSs and that after each CS-US pairing, there is less associative strength to share. This model explains blocking quite handily. Pretraining with the first CS leaves little or no associative strength left to accrue to the second CS during compound conditioning. This model captures Kamin's (1969) original perception that in order for an association to be formed between the CS and US, the US must be surprising; as the predictive

Correspondence concerning this article should be addressed to George A. Cicala, Department of Psychology, 220 Wolf Hall, University of Delaware, Newark, DE 19716. power of the CS is learned, the US becomes less and less surprising, and further conditioning diminishes.

Theories in the second category also utilize the notion of surprise, but emphasize changes in the processing of the CS. Mackintosh (1975b) proposed a model in which the salience of a CS is assumed to increase in proportion to how well it predicts the US; attention to the CS that best predicts reinforcement increases during conditioning, whereas attention to irrelevant stimuli declines. This process is assumed to occur proactively; that is, if a CS is a good predictor of the US on trial $n$, its salience will be increased on trial $n+1$. Pearce and Hall (1980) proposed a theory that also assumes proactive changes in CS processing, but, in contrast to Mackintosh's model, holds that attention declines to the CS that best predicts the US. Both of these theories effectively explain the blocking phenomenon. According to Mackintosh (1975b), a progressive increase in attention to the first CS occurs when it is paired with the US. When the second CS is added during compound training, it is a relatively poor predictor of the US, and attention to it rapidly declines; therefore, it acquires little associative strength. Pearce and Hall (1980) also maintained that attention to the added element will decline, resulting in no conditioning to that CS. Because both of these models assume that the decline in attention to the blocked CS is proactive, both assume that that CS is fully attended to on the first compound trial and that conditioning does occur. These models therefore predict a failure of blocking after one compound trial, a result obtained by Mackintosh (1975a). This would not be predicted by Rescorla and Wagner (1972), because according to their model sufficient pretraining renders the US incapable of supporting additional conditioning to the added CS, and this would be manifest on the first compound trial. Most of the evidence is in favor of blocking 
on the first compound trial (Azorlosa \& Cicala, 1986; Balaz, Kasprow, \& Miller, 1982; Gillan \& Domjan, 1977; Revusky, 1972).

Although blocking has been observed with one or several compound trials, it is rarely complete, in that some conditioning is usually observed to the added CS (see Azorlosa \& Cicala, 1986). The results of other studies show that conditioning to the blocked CS increases after the first compound trial. For example, Mackintosh, Bygrave, and Picton (1977) showed that the blocked CS elicited more suppression after two compound trials than after one. The most obvious associative explanation for incomplete blocking is incomplete conditioning to the pretrained element. If the pretrained CS were not fully conditioned, then additional associative strength would be available to the added CS, either because the US would still be somewhat effective (Rescorla \& Wagner, 1972) or because attention to the added CS would not diminish (Mackintosh, 1975b; Pearce \& Hall, 1980). The present experiments determined whether conditioning to a blocked CS would increase as a function of the number of compound trials after extensive pretraining. Six groups of rats were given shock pretraining with a noise CS followed by 1,10 , or 30 trials in which a noise-light CS was paired with shock. Half the animals were tested with the light $\mathrm{CS}$ and the other half were tested with the noise to measure the level of conditioning to the blocking CS.

\section{EXPERIMENT 1}

\section{Method}

Subjects. Seventy-two male Wistar rats were used. They were approximately 100 days old and weighed between 280 and $310 \mathrm{~g}$.

Apparatus. The conditioning chamber was $31 \mathrm{~cm}$ long, $15.5 \mathrm{~cm}$ wide, and $15.5 \mathrm{~cm}$ high. The long walls were constructed of aluminum and the short walls and top of Plexiglas. The floor was constructed of $0.23-$ $\mathrm{cm}$ stainless steel rods. One Plexiglas wall contained a circular hole, $1 \mathrm{~cm}$ in diameter, located $5.5 \mathrm{~cm}$ above the floor. This provided the rat with access to an electrically insulated drinking tube connected through a drinkometer circuit to the grid floor. Drinking closed the circuit, which was recorded by an Apple II computer that was also programmed to present all stimulus conditions during conditioning and testing.

The CS was either noise or light. Noise onset increased the ambient sound level from 41 to $80 \mathrm{~dB}$ (scale B) and was presented from a 17$\mathrm{cm}$ speaker located directly above the conditioning chamber. The light CS was provided by two 7-W bulbs located above the box. The US was a 2 -sec, $100-\mathrm{V}$ scrambled shock delivered by a $150-\mathrm{k} \Omega$ fixed impedance source. The entire apparatus was enclosed in a sound-attenuating box.

Procedure. The rats were deprived of water for $24 \mathrm{~h}$ before the experiment. On Day 1, the rats were placed in the apparatus and given 20 min access to the drinking tube. Conditioning trials were given on Days 2-4. On these days, the rats were first given 20 min access to the drinking tube; this made up their daily water ration. After 20 min, the drinking tube was removed. Five minutes later conditioning began. A conditioning trial consisted of a 10-sec CS interval, during the last $2 \mathrm{sec}$ of which shock was presented. At that point, the CS and US coterminated. There was an intertrial interval (ITI) of $45 \mathrm{sec}$. On Days 2 and 3 , all rats were given 10 noise conditioning trials. On Day 4, the rats were given 1,10 , or 30 simultaneous compound (noise-light) conditioning trials. All rats were tested for conditioned suppression on Day 5. Test (extinction) trials began after the rat emitted 400 licks. The first $10 \mathrm{sec}$ of a trial constituted the baseline. The CS was then presented for $10 \mathrm{sec}$ without shock. The number of licks in each 10 -sec interval was recorded and used to calculate suppression ratios $[\mathrm{A} /(\mathrm{A}+\mathrm{B})$, where $\mathrm{A}=$ licks during the $\mathrm{CS}$ interval and $\mathrm{B}=$ licks during the baseline $]$.
The ITI was $35 \mathrm{sec}$, making the temporal interval between CS presentations the same in testing as in training (ITI + baseline $=45 \mathrm{sec}$ ). There were four test trials. Half of the rats were tested with the light (L) $\mathrm{CS}$ and the other half with the noise $(\mathrm{N})$. The six groups were designated by the number of compound trials $(1,10$, or 30$)$ and the test CS ( $\mathrm{N}$ or $\mathrm{L}$ ).

\section{RESULTS AND DISCUSSION}

The left-hand panel of Figure 1 shows mean suppression ratios during the four test trials for the rats tested with the blocked CS (light). All three groups were fairly suppressed during Trial 1 and became less suppressed over Trials 2-4. The group that received one compound trial (1L) showed a more rapid release from suppression than did the groups that received $10(10 \mathrm{~L})$ or $30(30 \mathrm{~L})$ compound trials; the latter two groups appeared to be equal. All three groups evidenced little suppression on Trial 4. A $3 \times 4$ analysis of variance (ANOVA) (number of compound trials $\times$ number of test trials) showed a main effect for number of compound trials $[F(2,33)=7.84$, $p<.01]$ and test trials $[F(3,99)=46.79, p<.01]$. The interaction was not significant. A $3 \times 4$ ANOVA conducted on the baseline data showed no differences among the three groups. Newman-Keuls tests conducted on the ratios $(p<.05)$ confirmed the visual impression of Figure 1. Group 1L was less suppressed than Groups $10 \mathrm{~L}$ and $30 \mathrm{~L}$, which did not differ.

The greater amount of conditioning in the groups that received multiple compound trials than in the group that received one trial might have been a function of differential levels of conditioning to the blocking CS (noise). That is, the evidence of greater conditioning to the noise in the multiple compound trial groups than in the group given a single compound trial would suggest that additional conditioning occurred after the first compound trial and that both the light and the noise acquired more excitatory strength during these trials.

The data of the noise-tested groups are presented in the right-hand panel of Figure 1. All three groups were very

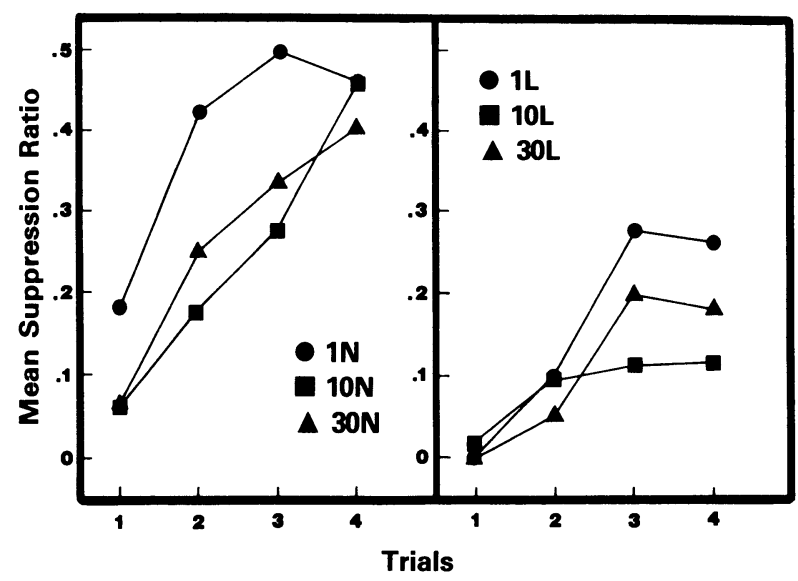

Figure 1. Mean suppression ratios during test trials in Experiment 1. Left panel: Groups tested with the light (blocked) CS. Right panel: Groups tested with the noise (blocking) CS. 
suppressed on the first two trials and became less so on the remaining two. The group that received one compound trial (1N) was somewhat less suppressed on Trials 3 and 4 than Group 30N, which was less so than Group $10 \mathrm{~N}$. A $3 \times 4$ ANOVA (number of compound trials $\times$ number of test trials) showed that these differences were not statistically reliable $[F(2,33)=1.19, p>.3]$. The effect for test trials was significant $[F(3,99)=14.42$, $p<.01]$, but the interaction was not. Subsequent Newman-Keuls tests revealed no difference in conditioning to the noise. That the noise-tested groups were equally suppressed suggests that the noise-shock association might have been at asymptote at the beginning of compound training after 20 noise-shock pairings. If this was true, then greater conditioning to the light in Groups $10 \mathrm{~L}$ and $30 \mathrm{~L}$ was not due to incomplete conditioning to the noise.

The pattern of responding to the noise, however, is similar to the pattern elicited by the light; that is, less conditioning was found in both of the groups given one compound trial than in the groups given multiple trials. Despite the fact that these differences were not significant, conditioning to the noise might not have been at asymptote at the beginning of compound training, which might have been responsible for the additional conditioning that occurred after pretraining.

Two approaches were used in Experiment 2 to address this issue. First, part of the experiment was a replication of the procedure used with the noise-tested groups of Experiment 1 . That is, after 20 pretraining trials, three groups received 1,10 , or 30 compound trials followed by testing with the noise. Since the failure to obtain significant differences in Experiment 1 might have been due to floor effects, extensive extinction testing, which might provide a more sensitive indication of group differences, was used in Experiment 2. If conditioning to the noise increased with additional compound training, this would suggest that the noise might not have been asymptotic at the start of compound training. However, a more straightforward test of the conditioning achieved during pretraining would be to give further training with the noise alone, rather than compounded with the light. The second approach used in Experiment 2 was therefore to give three groups 1,10 , or 30 additional noise-shock pairings in a procedure otherwise identical to that used with the groups that received compound training.

\section{EXPERIMENT 2}

\section{Method}

Subjects. Forty-eight male Wistar rats were used. They were about 100 days old and weighed between 270 and $310 \mathrm{~g}$.

Apparatus. The apparatus used in this experiment was the same as that used in Experiment 1.

Procedure. The deprivation, the water ration, and the general conditioning procedures were the same as those used in Experiment 1. All rats received 10 noise-shock conditioning trials on each of 2 days. On the third conditioning day, the rats received 1,10 , or 30 additional conditioning trials. For half the rats, these trials were noise-shock trials; the other half received compound conditioning consisting of a simultaneous noise-light $\mathrm{CS}$ followed by shock. On the following 3 days, all rats were tested for conditioned suppression to the noise. The six groups were designated by the number of trials following pretraining $(1,10$, or 30) and the type of CS presented during this phase, compound (C) or noise alone $(\mathrm{N})$.

\section{RESULTS AND DISCUSSION}

Figure 2 shows suppression ratios averaged across the 12 test trials. The three groups trained with the compound CS after pretraining (hatched bars) exhibit a pattern similar to that observed in Experiment 1: the group given one trial (1C) was slightly less suppressed than the other two groups. The groups that received additional training with the noise CS (filled bars) show a different pattern; that is, the group given one trial $(1 \mathrm{~N})$ was slightly more suppressed than the other two groups. A $2 \times 3$ ANOVA (CS $X$ test trials) showed that the small differences seen in Figure 2 were not reliable. Neither the effect for CS (noise vs. compound), the effect for the number of trials, nor the interaction approached significance (all $F_{\mathrm{s}}<1$ ).

Taken together, the results of Experiments 1 and 2 support the position that asymptotic conditioning to the noise was reached during pretraining. In both experiments, increased training with the compound CS produced no reliable differences in suppression elicited by the noise CS, even when extended testing was performed to reduce floor effects. Furthermore, the results for the groups trained only with the noise in Experiment 2 argue for the conclusion of asymptotic conditioning because additional training with the noise after pretraining produced no reliable differences; in fact, Group $1 \mathrm{~N}$ was slightly more suppressed than the other two groups. Although the null hypothesis cannot be proven, the fact that the original results of the compound-trained, noise-tested groups were replicated, and were also examined in a second way, provides strong support for this interpretation.

The increased conditioning to the light CS in Experiment 1 , in spite of asymptotic conditioning to the noise, could be interpreted as evidence for within-compound as-

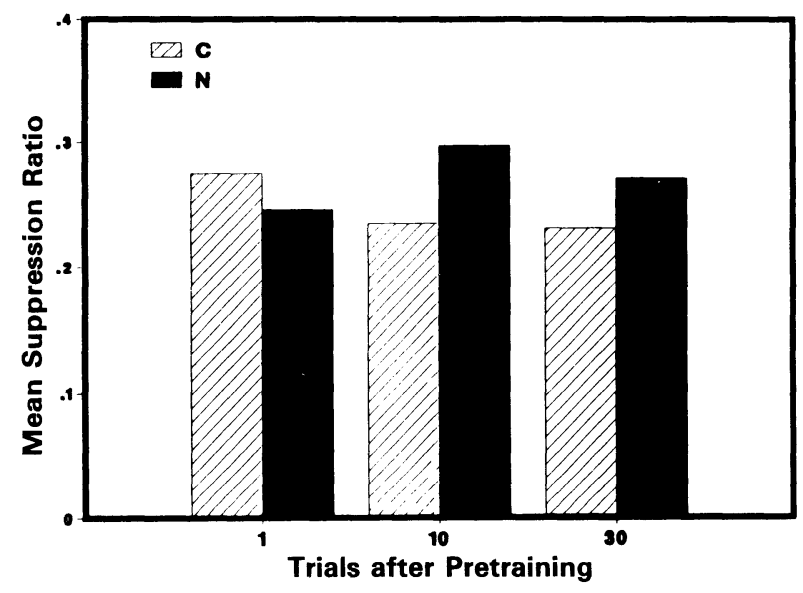

Figure 2. Mean suppression ratios during testing with the noise CS in Experiment 2. C: Groups trained with compund CS after pretraining. N: Groups trained with noise CS after pretraining. 
sociation (e.g., Rescorla, 1981; Rescorla \& Durlach, 1981); that is, the light might have acquired associative strength because of its pairing with the already conditioned noise. This is unlikely, however, because the formation of these associations is retarded when there is more than minimal exposure to one of the elements and when the US is presented during compound training (Rescorla \& Colwill, 1983; Rescorla \& Durlach, 1981). In an unpublished blocking study using the same parameters as described above, we found that extinction of the pretrained CS had no effect on conditioning to the blocked CS, suggesting that within-compound associations were not responsible for the results of Experiment 1 .

Assuming asymptotic conditioning to the pretrained CS (noise) and the absence of within-compound effects, the increased conditioning to the blocked CS (light) is not predicted by the theories discussed. According to the Rescorla-Wagner (1972) model, a US supports a limited amount of conditioning, which, if exhausted during pretraining, leaves none for the blocked CS. In the CS processing model of Pearce and Hall (1980), asymptotic conditioning of the pretrained CS results in zero associability of the blocked CS after the first compound trial, and thus no further conditioning to it. Mackintosh (1975b, 1978) also emphasized the first compound trial; according to his model, if an added CS is unaccompanied by a change in reinforcement, attention to it drops precipitously, and no additional conditioning to that CS is expected.

An argument could be made that although asymptote was reached by the noise CS during pretraining, the introduction of the light caused disinhibition or a generalization decrement, thus attenuating conditioning to the noise. This explanation, which is compatible with all three theories, deserves attention in light of the pattern of results of Experiment 2. Figure 2 shows that Groups $10 \mathrm{~N}$ and $30 \mathrm{~N}$ were slightly less suppressed than Group $1 \mathrm{~N}$, which suggests that additional training with the noise produced some habituation. The groups given additional compound training (10C and 30C) were slightly more suppressed than Group $1 \mathrm{C}$, and also more than Groups $10 \mathrm{~N}$ and $30 \mathrm{~N}$. This might have occurred because the introduction of the light allowed for more conditioning to both the noise and the light itself. However, the group differences seen in Figure 2 did not approach statistical reliability. The present experiments are interpreted as indicating that, regardless of pretraining with other stimuli, an added CS that reliably and repeatedly precedes a US will acquire some limited amount of conditioned excitatory strength.

\section{REFERENCES}

Azorlosa, J. L., \& Cicala, G. A. (1986). Blocking of conditioned suppression with 1 or 10 compound trials. Animal Learning \& Behavior, 14, 163-167.

Balaz, M. A., Kasprow, W. J., \& Miller, R. R. (1982). Blocking with a single compound trial. Animal Learning \& Behavior, 10, 271-276.

Gillan, D. J., \& Domjan, M. (1977). Taste-aversion conditioning with expected and unexpected drug treatment. Journal of Experimental Psychology: Animal Behavior Processes, 3, 297-309.

Kamin, L. J. (1969). Predictability, surprise, attention and conditioning. In B. A. Campbell \& R. M. Church (Eds.), Punishment and aversive behavior. New York: Appleton-Century-Crofts.

MACKINTOSH, N. J. (1975a). Blocking of conditioned suppression: Role of the first compound trial. Journal of Experimental Psychology: Animal Behavior Processes, 1, 335-345.

MaCKInTosh, N. J. (1975b). A theory of attention: Variations in the associability of stimuli with reinforcement. Psychological Review, 82, 276-298.

MACKINTOSH, N. J. (1978). Cognitive or associative theories of conditioning: Implications of an analysis of blocking. In S. H. Hulse, H. Fowler, \& W. K. Honig (Eds.), Cognitive processes in animal behavior. Hillsdale, NJ: Erlbaum.

Mackintosh, N. J., Bygrave, D. J., \& Picton, B. M. (1977). Locus of the effect of a surprising reinforcer in the attenuation of blocking. Quarterly Journal of Experimental Psychology, 29, 327-336.

Pearce, J. M., \& Hall, G. A. (1980). A model of Pavlovian learning: Variation of the effectiveness of conditioned but not of unconditioned stimuli. Psychological Review, 87, 532-552.

Rescorla, R. A. (1981). Simultaneous associations. In P. Harzem \& M. Zeiler (Eds.), Advances in analysis of behavior (Vol. 2). New York: Wiley.

Rescorla, R. A., \& Colwill, R. M. (1983). Within-compound associations in unblocking. Journal of Experimental Psychology: Animal Behavior Processes, 9, 390-400.

Rescorla, R. A., \& Durlach, P. M. (1981). Within-event learning in Pavlovian conditioning. In N. E. Spear \& R. R. Miller (Eds.), Information processing in animals: Memory mechanisms. Hillsdale, $\mathrm{NJ}$ : Erlbaum.

Rescorla, R. A., \& Wagner, A. R. (1972). A theory of Pavlovian conditioning: Variations in the effectiveness of reinforcement and nonreinforcement. In A. Black \& W. F. Prokasy (Eds.), Classical conditioning II: Current research and theory. New York: AppletonCentury-Crofts.

REVUSKY, S. H. (1971). The role of interference in association over delay. In W. K. Honig \& P. H. R. James (Eds.), Animal memory. New York: Academic Press.

(Manuscript received for publication September 21, 1987.) 